\title{
Anxiety of parents and children in dental care
}

\section{Ansiedade dos pais e crianças no tratamento odontológico}

\author{
José Maria Chagas VIANA FILHO' ${ }^{1}$ D 0000-0002-5922-1217 \\ Marayza Alves CLEMENTINO² iD 0000-0002-9552-4901 \\ Larissa Chaves Morais de LIMA $^{2}$ iD 0000-0002-9351-5438 \\ Ana Flávia Granville GARCIA² iD 0000-0002-6054-8372 \\ Margarida Maria Pontes de CARVALHO3 ${ }^{3}$ 0000-0001-9552-9983 \\ Jainara Maria Soares FERREIRA ${ }^{3}$ iD 0000-0001-7040-7197
}

\begin{abstract}
Objective: To verify the prevalence and association of parents' and children's anxiety concerning socioeconomic variables and child's behavior during dental care. Methods: This was a quantitative, observational, transversal and descriptive study. Data collection was performed through a questionnaire aiming at sociodemographic data and dental experience as well as Venham Picture Test, Corah Dental Anxiety Scales and Frankl Anxiety Scale. Data were analyzed using descriptive and inferential statistics (Chi-square and Fisher's exact test), $\alpha=0.05$. Results: The sample consisted of 7 to 9 year- old children $(57.9 \%$.), of whom $72.6 \%$ were submitted to invasive procedures. The prevalence of anxiety among children was $43.2 \%(n=41)$. Regarding parents / guardians, the prevalence of anxiety was $88.4 \%(n=84)$. A significant association was found between the dental appointment experience and the child's anxiety ( $p=$ $0.050)$ using the VPT. A significant association between anxiety and the type of dental procedure $(p=0.017)$ as well as the child's experience $(p=0.000)$ using the Frankl scale. Conclusion: There was no association between anxiety and socioeconomic variables. In the variables related to dental experiences, a significant association was found between the experience of the dental appointment and the anxiety of the child using the VPT scale. An association between anxiety and the type of procedure was observed, as well as dental appointment experience, using Frankl scale.
\end{abstract}

Indexing terms: Anxiety scale. Children. Dental anxiety. Pediatric dentistry.

\section{RESUMO}

Objetivo: Verificar a prevalência e a associação da ansiedade dos pais e filhos entre as variáveis socioeconômicas frente ao comportamento da criança durante o atendimento odontológico. Métodos: Este estudo foi caracterizado como quantitativo, observacional, transversal e descritivo. Para a coleta de dados, utilizou-se um questionário sobre dados sociodemográficos e experiência dentária, Escalas de Teste de Imagem de Venham, Escalas de Ansiedade Odontológica de Corah e Escala de Ansiedade de Frankl. Os dados foram analisados utilizando estatística descritiva e inferencial (Qui-quadrado e Teste exato de Fisher), $\alpha=0.05$. Resultados: A maioria das crianças pertencia à faixa etária de 7 a 9 anos, 57,9\%. Destas, 72,6\% foram submetidos a procedimentos invasivos. A prevalência de ansiedade das crianças foi de 43,2\% (n=41). Quanto aos pais/responsáveis, a prevalência de ansiedade foi de 88,4\% ( $n=84$ ). Foi verificada

\section{$\boldsymbol{\nabla v} \mathbf{v}$}

${ }^{1}$ Centro Universitário de João Pessoa, Curso de Odontologia. João Pessoa, PB, Brasil.

2 Universidade Estadual da Paraíba, Departamento de Odontologia. Campina Grande, PB, Brasil.

3 Faculdades de Medicina e Enfermagem Nova Esperança, Curso de Odontologia. Av. Frei Galvão, 12, Valentina, 58067-695, João Pessoa, PB, Brasil. Correspondência para / Correspondence to: JMS FERREIRA. E-mail: <jainara.sf@gmail.com>.

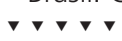

Viana Filho JMC, Clementino MA, Lima LCM, Garcia AFG, Carvalho MMP, Ferreira JMS. I. Anxiety of parents and children in dental care. RGO, Rev Gaúch Odontol. 2018;66(4):321-329. http://dx.doi.org/10.1590/1981-863720180004000053483 
associação significativa entre experiência da consulta e ansiedade da criança $(p=0,050)$ utilizando a escala VTP. E foi verificada associação significativa entre a ansiedade e o tipo de procedimento $(p=0,017)$ e a experiência da criança $(p=0,000)$ utilizando a escala de Frankl. Conclusão: Não houve associação entre ansiedade e as variáveis socioeconômicas. Nas variáveis relacionadas as experiências odontológicas, foi verificada associação significativa entre a experiência da consulta e a ansiedade da criança utilizando a escala VTP. Na escala de Frankl foi observada associação entre ansiedade e o tipo de procedimento, e experiência da consulta.

Termos de indexação: Escala de ansiedade manifesta. Crianças. Ansiedade ao tratamento odontológico. Odontopediatria.

\section{INTRODUCTION}

Anxiety and fear associated with dental treatments are different psychological stages which are related to patients. Anxiety is described as a reaction to the feeling of danger or apprehension in situations prior to the dental treatment. On the other hand, fear is generally considered as a physiological, behavioral and emotional response to a dreaded stimulus. The literature has sought answers to alleviate fear and anxiety during dental treatments $[1,2]$. Anxiety and fear during the dental appointment vary with age, sex, educational level and socioeconomic factors [2]. Contrary to popular belief, the prevalence of anxiety prior to dental treatment does not decrease with age [3]. The prevalence of anxiety in children during dental treatments can reach up to $29 \%[4,5]$.

The high level of anxiety during dental treatments has been associated with caries lesions and poor oral health [6]. In addition, the studies have reported that negative experiences during dental treatment can induce fear and anxiety among children. Moreover studies have also shown that parents who are fearful and anxious about dental treatments are associated with an increase in the occurrence of caries disease in their children, since they are more resistant to accompany their children to the dentist [4]. Studies reveal a strong association between fear and anxiety among children and parental dental fear with the child's behavior $[7,8]$ which show that parents can contribute to anxiety and fear development in children [6]. For this reason, it is necessary to identify and quantify fear and anxiety in the dental treatment and to monitor its effect [9].

Assessing anxiety and fear in children and their parents / guardians is a difficult task. Venham Picture Test (VPT) is commonly used to assess a child's anxiety before dental care. The VPT uses eight charts, each of which shows two images presenting opposing feelings $[10,11]$. Corah Dental Anxiety Scale is a psychometric instrument consisted of a more detailed, short and validated questionnaire, specifically designed for dental anxiety measurement in adults [12]. Some studies have shown that this scale can be faithfully used to measure the dental anxiety of parents who accompany their children in the dental clinic $[13,14]$. This scale divides patients as follows: anxiety free, low anxiety, medium anxiety and high levels of anxiety $[12,15]$. Dentists often use the Frankl behavior classification scale, which assesses the behavior of children during dental care based on the dentist's observation. This scale is composed of four behavioral categories: (1) strictly positive; (2) positive; (3) negative; (4) strictly negative [16].

The pediatric dentists' knowledge about dental anxiety is of utmost importance in order to better understand children's behavior during treatment as well as to encourage clinicians to use psychological strategies so that both children's and parents' confidence is increased. For this, new studies are essential in order to clarify which variables may be associated with the children's anxiety levels as well as their parents/guardians. The objective of this study was to verify the prevalence and the association of parents' and children's anxiety levels concerning socioeconomic variables in relation to the child's behavior during dental care.

\section{METHODS}

\section{The sample features}

This quantitative, observational, transversal and descriptive study consisted of a sample size based on the prevalence of anxiety among children reported in the study by Oliveira et al. [17]. The sample was as follows: 127 children aged from 4 to 9 years old attending the children's clinic of the School of Dentistry of the University Center of João Pessoa - UNIPÊ. The prevalence considered was $48.3 \%$, maximum acceptable error of $5 \%$ and level of significance of $95 \%$. In this study, the sample consisted of 95 children, as well as 95 parents/guardians calculated using Epi info 7.0. 


\section{Ethical aspects}

The research was approved by the Ethics and Research Committee on Human Beings of the University Center of João Pessoa - UNIPÊ, under number 682/2015 CAAE: 48845915.0 .0000 .5176 and 1,257,355, following the resolution n. 466/2012 of the National Health Coun.

\section{Eligibility criteria}

The inclusion criteria consisted of children, age ranging from 4 to 9 years old, both sexes, attending the Children's Clinic. Those who did not have cognition to respond to the anxiety test or were not authorized by parents were excluded.

Parents' criteria included those over 18 years old, of both genders and those who could not respond to the research tools were excluded.

\section{Calibration and training}

Two examiners received gold standard calibration in the research area and then calibrated to each other. The calibration was divided into two steps: - First Step: the questionnaires and study variables were presented; $\bullet$ Second Step: a final discussion of the questions and possible answers to the questionnaire in which the examiners were judged fit for the data collection.

The questionnaire on the parents' and children's socioeconomic data and the previous dental child experience was elaborated by the researcher in charge of the study and examiners especially chosen for this study.

\section{Data collection}

Data collection instruments were those previously used by Oliveira et al. [17] in order to assess anxiety in the child and the parents / guardians before dental treatment.

The following questionnaires were used: Modified Venham Picture Test (MVPT), Corah Dental Anxiety Scale, and Frankl Anxiety Scale. In addition, socioeconomic data and previous dental experience of the child and the parents / guardians were collected. In order to assess the child's anxiety, the modified VPT scale was used, in which the child was asked clearly by the examiner: "Show me how you feel now!". Eight pairs of a child's picture shown in the chart, were presented where each picture depicted some feeling the child might be experiencing at that moment. Each figure which, in each pair revealed a negative feeling, was assessed from 0 to 8 . In this case, the sum of the assessment of all pairs of figures was categorized as zero for anxiety-free children; one to three as low anxiety level; four to six, medium level of anxiety and seven and eight as highly anxious [10]. The Corah Dental Anxiety Scale, an adult dental anxiety questionnaire was presented for parents and guardians, which shows four questions presenting five possible answers. The score can vary from 4 to anxiety-free patient, up to 20 to very anxious patient. The classification used proposes four categories for anxiety, as follows: Anxiety free (4 to 5 points), Low anxiety level (6 to 10 points), Medium anxiety level (11 to 15 points) and High anxiety level (16 to 20 points).

After children and parents received the anxiety test application, the calibrated examiners evaluated the children's behavior during dental appointment using Fankl Scale. This scale is composed of four behavioral categories: (1) strictly positive - presents good rapport between dentist-patient, interested in dental procedures, laughing and appreciating the situation [16], (2) positivepresents acceptance of treatment, willingness to obey the dentist,cooperative, follows the dentist's instructions (3) negative- presents reluctance to accept treatment, without any cooperation, evidence of a negative, that is, angry and withdrawn. (4) strictly negative - rejection of treatment, crying vigorously, fearful or some other evidence of negative behavior.

There were no health risks for parental and child participation in this study, and the research could be discontinued if the participant felt any discomfort or embarrassment during the study. It can be highlighted as the study benefits: planning of the behavioral management of children during the dental care, allowing the performance of safe dental procedures which provided good quality care for the sample.

\section{Statistical analysis}

The data collected were analyzed by the statistical software SPSS v.20.0. Descriptive statistical analyzes were performed using absolute numbers and percentages and 
by inferential statistics, using the Chi square test, Pearson accurate test and Fisher's accurate test, with a significance level of $5 \%$, when duly indicated.

\section{RESULTS}

Table 1 shows the sample characteristics in which 95 children age range from 4 to 9 years old participated in this study. The majority belonged to the age group aged from 7 to 9 years old, $57.9 \%(n=55)$ of the total.

Regarding the sex of the interviewees, $52.6 \%(n=$ 50 ) of the children were males and the majority of parents / guardians were female, corresponding to $87.4 \%(n=83)$. As the level of schooling is concerned, $26.3 \%(n=25)$ of parents / guardians reported being illiterate or having elementary education. The majority reported receiving family income of up to 2 minimum wages $(73.7 \%, n=70)$.

Table 1 also provides information regarding children's and parents' anxiety levels. It was verified that $88.4 \%(n=84)$ of the children had previously been to a dental appointment, of whom $-41.1 \%(n=39)$ were assisted by pediatric dentists. Approximately $72.6 \%(n=$ 61) underwent invasive procedures and $61.9 \%(n=52)$ presented positive experiences during dental care. The prevalence of anxiety in children was $43.2 \%(n=41)$, of whom $5.3 \%(n=5)$ demonstrated a high level of anxiety. As for parents and guardians, the prevalence of anxiety was $88.4 \%(n=84)$, and the majority presented a low anxiety level of $53.7 \%(n=51)$.

Table 2 presents information on the association between socioeconomic variables and odontological experiences with the MVPT Scale. There was no association between socioeconomic variables ( $p>0.05$ ). However, in the variables related to dental experiences, a significant association between the experience of the appointment (positive or negative) and the anxiety of the child was verified $(p=0.050)$.

Table 3 shows information on the association between socioeconomic variables and dental experiences with the categorized FrankI Scale. There were no significant associations between socioeconomic variables. However, there was a significant association between anxiety and the type of procedure $(p=0.017)$ and the child's experience whether positive or negative- $(p=0.000)$.

\section{DISCUSSION}

Anxiety and fear that precedes dental treatment can cause children and parents to avoid going to the dentist. In addition, they may be the reasons for negative behavior during dental care, and therefore considered risk factors concerning oral problems $[5,6]$. This study has shown high prevalence of dental anxiety in children. However, when anxiety into levels was categorized, high anxiety presented low prevalence compared to other studies which also evaluated school-age children $[5,14]$. In these studies, the prevalence rate of high anxiety before dental care ranged from $2.6 \%$ to $29.3 \%$ which can be attributed to the methodological diferences such as variations between the scales of measurement of the level of anxiety, and variations in the age group of the studied group.

The anxiety of parents and guardians was classified into four levels, most of which were considered as low and medium level of anxiety during dental care corroborating with the results of other studies [14-18]. Childhood anxiety may be associated with maternal anxiety which may result in non-collaborative attitudes of children [19]. The parents' anxiety may also influence the psychological preparation of the child undergoing dental care and consequently impair the treatment [20].

Some studies report that children whose parents have lower family income are more likely to present anxiety during dental care when compared to families with higher income $[21,22]$. Previous studies have also shown that higher family income is associated with a lower prevalence of dental anxiety $[4,23]$. Unlike most of the studies, there was no significant association between socioeconomic factors and anxiety levels of the child and their parents/ guardians, since most of the children's parentes evaluated presented low income, between one and two minimum income wages. Consequently, these children were less likely to receive dental treatments, and therefore more collaborative children. Another point of view is that most of the children evaluated came from the same socioeconomic level, impairing associations.

Regarding dental care anxiety and the levels of education, the literature is ambiguous. Gustafsson et al. [23] point out to these associations, however Cagiran et al. [19] disagree that there is an association between levels of schooling and children's anxiety and their parents/ guardians, in agreement with the findings of this study. In 
Table 1. Sample characteristics. João Pessoa (PB), 2017.

\begin{tabular}{|c|c|}
\hline Variables & Frequency n (\%) \\
\hline 4 to 6 years old & $40(41.2)$ \\
\hline 7 to 9 years old & $55(57.9)$ \\
\hline \multicolumn{2}{|l|}{ Children's sex } \\
\hline Male & $50(52.6)$ \\
\hline \multicolumn{2}{|l|}{ Guardian's sex } \\
\hline Male & $12(12.6)$ \\
\hline Female & $83(87.4)$ \\
\hline \multicolumn{2}{|l|}{ Family income } \\
\hline Junior High & $25(26.3)$ \\
\hline High School & $70(73.3)$ \\
\hline \multicolumn{2}{|c|}{ Has your child been to the dentist? If yes, please answer the 3 following questions } \\
\hline Yes & $84(88.4)$ \\
\hline No & $11(11.6)$ \\
\hline \multicolumn{2}{|c|}{ Was the professional a pediatric dentist?* } \\
\hline Yes & $39(41.1)$ \\
\hline No & $45(47.4)$ \\
\hline \multicolumn{2}{|c|}{ What kind of dental procedure was it?* } \\
\hline Negative & $32(38.1)$ \\
\hline \multicolumn{2}{|c|}{ Child's anxiety prevalence ( MVPT) } \\
\hline Anxiety free & $54(58.8)$ \\
\hline Anxious & $41(43.2)$ \\
\hline \multicolumn{2}{|c|}{ Children's anxiety level (MVPT) } \\
\hline Anxiety free & $54(58.8)$ \\
\hline Low level of anxiety & $25(26.3)$ \\
\hline Average level of anxiety & $11(11.6)$ \\
\hline High level of anxietey & $5(5.3)$ \\
\hline \multicolumn{2}{|c|}{ Parents' anxiety prevalence ( Corah Scale) } \\
\hline Anxiety free & $11(11.6)$ \\
\hline Anxious & $84(88.4)$ \\
\hline \multicolumn{2}{|c|}{ Parents' level of anxiety ( Corah Scale) } \\
\hline Anxiety free & $11(11.6)$ \\
\hline Low level of anxiety & $51(53.7)$ \\
\hline Medium levem of anxiety & $29(30.5)$ \\
\hline High level of anxiety & $4(4.2)$ \\
\hline
\end{tabular}


Table 2. Association between socioeconomic variables and the MVPT Scale. João Pessoa (PB), 2017.

\begin{tabular}{|c|c|c|c|c|c|c|}
\hline \multirow{3}{*}{ Variables } & & \multicolumn{4}{|c|}{ MVPTM Scale } & \multirow{3}{*}{ P value } \\
\hline & & \multicolumn{2}{|c|}{ Low or no anxiety } & \multicolumn{2}{|c|}{ Medium or high anxiety } & \\
\hline & & $\mathrm{n}$ & $\%$ & $\mathrm{n}$ & $\%$ & \\
\hline \multirow[t]{2}{*}{ Family income } & Up to 2 minimum wages & 55 & 72.4 & 15 & 93.8 & $\mathrm{p}^{(2)}=0.105$ \\
\hline & More than 2 minimum wages & 21 & 27.6 & 1 & 6.2 & \\
\hline \multirow[t]{2}{*}{ Parents' education } & Illiterate/Elementary/ & 19 & 24.1 & 6 & 37.5 & $p^{(1)}=0.265$ \\
\hline & High School/University & 60 & 75.9 & 10 & 62.5 & \\
\hline \multirow[t]{2}{*}{ Parents'age } & Up to 30 years old & 29 & 36.7 & 6 & 37.5 & $\mathrm{p}^{(1)}=1.000$ \\
\hline & Over 30 years old & 50 & 63.3 & 10 & 62.5 & \\
\hline \multirow[t]{2}{*}{ Sex of parents } & Male & 9 & 11.4 & 3 & 18.8 & $p^{(1)}=0.419$ \\
\hline & Female & 70 & 88.6 & 13 & 81.2 & \\
\hline \multirow[t]{2}{*}{ Children's age } & 4 to 6 years old & 31 & 39.2 & 9 & 58.2 & $\mathrm{p}^{(1)}=0.209$ \\
\hline & 7 to 9 years old & 48 & 60.8 & 7 & 43.8 & \\
\hline \multirow[t]{2}{*}{ Sex of children } & Male & 42 & 53.2 & 8 & 50.0 & $p^{(1)}=0.817$ \\
\hline & Female & 37 & 46.8 & 8 & 50.0 & \\
\hline \multirow[t]{2}{*}{ Visit to the dentist } & Yes & 72 & 91.1 & 12 & 75.0 & $p^{(2)}=0.086$ \\
\hline & No & 7 & 8.9 & 4 & 25.0 & \\
\hline \multirow[t]{2}{*}{ Pediatric dentist } & Yes & 35 & 48.6 & 4 & 33.3 & $\mathrm{p}^{(2)}=0.367$ \\
\hline & No & 37 & 51.4 & 8 & 66.7 & \\
\hline \multirow[t]{2}{*}{ Type of procedure } & invasive & 51 & 70.8 & 10 & 83.3 & $\mathrm{p}^{(2)}=0.497$ \\
\hline & preventive & 21 & 29.2 & 2 & 16.7 & \\
\hline \multirow[t]{2}{*}{ Experience } & Negative & 24 & 33.3 & 8 & 6.7 & $\mathrm{p}^{(2)^{\star}}=0.050$ \\
\hline & Positive & 48 & 66.7 & 4 & 33.3 & \\
\hline Total & & 79 & 83.2 & 16 & 16.8 & \\
\hline
\end{tabular}

Note: ${ }^{1}$ Using Pearson's Chi square, ${ }^{2}$ Using Exact Fisher ${ }^{*}$ Significant at $5 \%$

our research, there was no association between the level of maternal schooling and anxiety during the children's dental treatment. Our sample was based on the children's clinic of a university center, in a non-randomized way, which may have led to some bias as the selection of parents / guardians presenting elementary education. This may justify this non-association once it is believed that higher educational levels of parents increase the use of dental treatment of parents and children, thus resulting in low levels of anxiety [15].

There was no significant association between anxiety and the age of the children. Similar to the reports by Arapostathis et al. [24] and Rajwar and Goswami [25], who agree that anxiety is not related to the age difference between children, although other studies believe that dental anxiety may decrease with increasing age $[26,27]$. Previous studies have shown that anxiety during dental treatment in children is strongly associated with traumatic dental experiences and negative dental experiences $[9,28,29]$. This study obtained similar results for the variable negative experiences, using two different scales of anxiety measurement, the VPT Scale and Frankl scale. Both concluded that negative experiences are significantly associated with anxiety during dental treatments. Our study showed that only the Frankl scale obtained a significant association related to dental anxiety. Studies report that patients become more anxious when they are submitted to more invasive treatments such as oral surgery $[15,30]$. Moreover, studies report that this association is also related to other procedures which cause fear in children, among them: periodontal scraping and endodontic treatments using sharp objects, high rotation and drill vibrations in the oral cavity $[16,25]$.

In this study, the type of experience (positive or negative) during dental care was also statistically significant when related to anxiety. Abanto et al. [6] demonstrated 
Table 3. Association between socioeconomic variables and the Frankl scale. João Pessoa (PB), 2017.

\begin{tabular}{|c|c|c|c|c|c|c|}
\hline \multirow{2}{*}{ Variables } & & \multicolumn{4}{|c|}{ Frankl Scale } & \multirow{2}{*}{$P$ value } \\
\hline & & $\mathrm{n}$ & $\%$ & $\mathbf{n}$ & $\%$ & \\
\hline \multirow[t]{2}{*}{ Family income } & Up to 2 minimum wages & 53 & 74.6 & 17 & 8.0 & $\mathrm{p}^{(2)}=0.772$ \\
\hline & More than 2 minimum wages & 18 & 25.4 & 4 & 19.0 & \\
\hline \multirow[t]{2}{*}{ Parents's age } & Up to 30 years old & 26 & 35.1 & 9 & 42.9 & $p^{(1)}=0.517$ \\
\hline & Over 30 years old & 48 & 64.9 & 12 & 57.1 & \\
\hline \multirow[t]{2}{*}{ Sex of parents } & Male & 9 & 12.2 & 3 & 14.3 & $\mathrm{p}^{(2)}=0.724$ \\
\hline & Female & 65 & 87.8 & 18 & 85.7 & \\
\hline Sex of children & Female & 38 & 51.4 & 7 & 33.3 & \\
\hline \multirow[t]{2}{*}{ Visit to the dentist } & Yes & 65 & 87.8 & 19 & 90.5 & $\mathrm{p}^{(2)}=1.000$ \\
\hline & No & 9 & 12.2 & 2 & 9.5 & \\
\hline \multirow[t]{2}{*}{ Pediatric dentist } & Yes & 28 & 43.1 & 11 & 57.9 & $\mathrm{p}^{(1)}=0.255$ \\
\hline & No & 37 & 56.9 & 8 & 42.1 & \\
\hline \multirow[t]{2}{*}{ Type of procedure } & invasive & 43 & 66.2 & 18 & 94.7 & $p^{(2)^{*}}=0.017$ \\
\hline & preventive & 22 & 33.8 & 1 & 5.3 & \\
\hline \multirow[t]{2}{*}{ Experience } & Negative & 17 & 26.2 & 15 & 78.9 & $\mathrm{p}^{(2)^{*}}=0.000$ \\
\hline & Positive & 48 & 73.8 & 4 & 21.1 & \\
\hline
\end{tabular}

Note: ${ }^{1}$ Using Pearson's Chi square, ${ }^{2}$ Using Exact Fisher ${ }^{*}$ Significant at 5\%.

that the experiences in previous dental appointments concerned lower levels of anxiety, since the children were previously aware of the treatment. Children presenting negative experiences related with high levels of anxiety are prone to not cooperate during care. Fear and anxiety about dental treatment may result in missed visits to the pediatric dentistry and delays to treatment, worsening oral problems [14].

The present study presents limitations inherent to cross-sectional studies. The size of the sample does not allow the extrapolation of the results to the general population. For this reason, future studies with a representative sample size are required. In addition, the age range of 4 to 9 years old may also be a limitation once younger or older children may have another perception of anxiety about dental treatment.

Despite the need for further studies in order to identify the importance of each variable in the dental anxiety levels of children and parentes/guardians, the findings have provided relevant information regarding the main factors associated with dental anxiety in preschoolers. This could help dentists to better understand children's behavior in dental settings, as well as encourage clinicians to use psychological strategies in order to increase children's confidence concerning anxiety during dental treatment

\section{CONCLUSION}

The prevalence of anxiety among children and parents/guardians was high, however the level of high anxiety was low for both variables. There was no association between socioeconomic variables. However, in the variables related to dental experiences, a significant association was found between the experience of the consultation (positive or negative) and the anxiety of the child using the VPT scale. When Frankl scale was used it 
was observed a significant association between the type of procedure and the experience of the consultation associated with anxiety during dental care.

\section{Collaborators}

JM CHAGAS and VIANA participated in data collection and writing of the article. JMS FERREIRA, MMP CARVALHO and AF GRANVILLE-GARCIA participated in the writing, data analysis and final reading of the article. MA CLEMENTINO and LCM LIMA participated in the writing and data collection.

\section{REFERENCES}

1. Armfield JM, Spencer AJ, Stewart JF. Dental fear in Australia: who's afraid of the dentist? Aust Dent J. 2006;51(1):78-85. https://doi.org/10.1111/j.1834-7819.2006.tb00405.x

2. Yildirim TT. Evaluating the Relationship of Dental Fear with Dental Health Status and Awareness. J Clin Diagn Res. 2016;10(7):105-109. https://doi.org/10.7860/JCDR/2016/19 303.8214

3. Soares FC, Lima RA, de Barros MVG, Dahllöf G, Colares $V$. Development of dental anxiety in schoolchildren: $A$ 2-year prospective study. Community Dent Oral Epidemiol. 2017;45(3):281-88. https://doi.org/10.1111/cdoe.12290

4. Colares V, Franca C, Ferreira A, Amorim Filho HA, Oliveira MC. Dental anxiety and dental pain in 5- to 12-year-old children in Recife, Brazil. Eur Arch Paediatr Dent. 2013;14:15-19. https:// doi.org/10.1007/s40368-012-0001-8

5. Paryab M, Hosseinbor M. Dental anxiety and behavioral problems: a study of prevalence and related factors among a group of Iranian children aged 6-12. J Indian Soc Pedod Prev Dent. 2013;31:82-6. https://doi.org/10.4103/0970-438 8.115699

6. Abanto J, Vidigal EA, Carvalho TS, Sá SN, Bönecker M. Factors for determining dental anxiety in preschool children with severe dental caries. Braz Oral Res. 2017;16;31(0):e13. https://doi.org/10.1590/1807-3107BOR-2017

7. Themessl-Huber M, Freeman R, Humphris G, MacGillivray $S$, Trezi N. Empirical evidence of the relationship between parental and child dental fear: a structure review and metaanalysis. Int J Paediatr Dent. 2010;20:83-101. https:// doi.org/10.1111/j.1365-263X.2009.00998.x

8. Olak J, Saag M, Honkala S, Nõmmela R, Runnel R, Honkala $\mathrm{E}$, et al. Children's dental fear in relation to dental health and parental dental fear. Stomatologija. 2013;15(1):26-31. https://doi.org/10.1186/s12903-018-0553-z

9. Ten Berge M, Veerkamp JS, Hoogstraten J. The etiology of childhood dental fear: the role of dental and conditioning experiences. J Anxiety Disord. 2002;16(3):321-329. https:// doi.org/10.1016/S0887-6185(02)00103-2

10. Venham LL, Gaulin-Kremer E. A self-report measure of situational anxiety for young children. Pediatr Dent. 1979;1(2):91-6.
11. Ramos-Jorge J, Marques LS, Homem MA, Paiva SM, Ferreira MC, Oliveira Ferreira F, et al. Degree of dental anxiety in children with and without toothache: prospective assessment. Int J Paediatr Dent. 2013;23(2):125-30. https://doi.org/10.1111/J.1 365-263X.2012.01234.x

12. Corah NL. Development of a dental anxiety scale. J Dent Res. 1969;48(4):596. https://doi.org/10.1177/0022034569048004 1801

13. Coric A, Banozic A, Klaric M, Vukojevic K, Puljak L. Dental fear and anxiety in older children: an association with parental dental anxiety and effective pain coping strategies. J Pain Res. 2014;20(7):515-521. https://doi.org/10.2147/JPR.S67692

14. Busato P, Garbín RR, Santos CN, Paranhos LR, Rigo L. Influence of maternal anxiety on child anxiety during dental care: cross-sectional study. Sao Paulo Med J. 2017;135(2):116-22. https://doi.org/10.1590/1516-3180.2016.027728102016

15. Egbor PE, Akpata O. An evaluation of the sociodemographic determinants of dental anxiety in patients scheduled for intraalveolar extraction. Libyan J Med. 2014;9:25433. https://doi. org/10.3402/ljm.v9.25433

16. Kilinç G, Akay A, Eden E, Sevinç N, Ellidokuz H. Evaluation of children's dental anxiety levels at a kindergarten and at a dental clinic. Braz Oral Res. 2016; 18;30(1). https://doi. org/10.1590/1807-3107BOR-2016.vol30.0072

17. Oliveira MF, Moraes MVM, Evaristo PCS. Avaliação da Ansiedade dos Pais e Crianças frente ao Tratamento Odontológico. Pesq Bras Odontoped Clin Integr. 2012;12(4);483-89. https://doi. org/10.4034/PBOCI.2012.124.06

18. de Carvalho RW, Falcão PG, Campos GJ, Bastos Ade S, Pereira $J C$, Pereira MA, et al. Anxiety regarding dental treatment: prevalence and predictors among Brazilians. Cien Saude Coletiva. 2012;17(7):1915-22. https://doi.org/10.1590/S141 3-81232012000700031

19. Cagiran E, Sergin D, Deniz MN, Tanattı B, Emiroglu N, Alper I. Effects of sociodemographic factors and maternal anxiety on preoperative anxiety in children. J Int Med Res. 2014;42(2):572-80. https://doi.org/10.1177/0300060513503758

20. Moura BF, Imparato JCP, Parisotto TM, De Benedetto M. Child's anxiety preceding the dental appointment: evaluation through a playful tool as a conditioning feature. RGO, Rev Gaúch Odontol. 2015;63(4):455-60. https://doi. org/10.1590/1981-863720150003000122848

21. Oliveira MMT, Colares V. The relationship between dental anxiety and dental pain in children aged 18 to 59 months: a study in Recife, Pernambuco state, Brazil. Cad Saude Publica 2009;25(4):743-50. https://doi.org/10.1590/S0102-3 $11 \times 2009000400005$

22. Soares FC, Lima RA, Santos Cda F, de Barros MV, Colares V. Predictors of dental anxiety in Brazilian 5-7years old children. Compr Psychiatry. 2016;67:46-53. https://doi.org/10.1016/j. comppsych.2016.01.006

23. Gustafsson A, Arnrup K, Broberg AG, Bodin L, Berggren U. Psychosocial concomitants to dental fear and behaviour management problems. Int J Paediatr Dent. 2007;17:449-59. https://doi.org/10.1111/j.1365-263X.2007.00883.x 
24. Arapostathis KN, Coolidge T, Emmanouil D, Kotsanos N. Reliability and validity of the Greek version of the children's fear survey schedule-dental subscale. Int J Paediatr Dent. 2008;18:374-379. https://doi.org/10.1111/j.1365-263X.200 7.00894.x

25. Rajwar AS, Goswami M. Prevalence of dental fear and its causes using three measurement scales among children in New Delhi. J Indian Soc Pedod Prev Dent. 2017;35(2):128-33. https://doi.org/10.4103/JISPPD.JISPPD_135_16

26. Akbay Oba A, Dülgergil CT, Sönmez IS. Prevalence of dental anxiety in 7- to 11-year-old children and its relationship to dental caries. Med Princ Pract. 2009;18(6):453-7. https://doi. org/10.1159/000235894

27. Laki K, Beslot-Neveu A, Wolikow M, Davit-Béal T. Child dental care: what's about parental presence?. Arch Pediatr. 2010;17(11):1617-24. https://doi.org/10.1016/j.arcped.2010. 07.016
28. Ten Berge M, Veerkamp JS, Hoogstraten J. The etiology of childhood dental fear: the role of dental and conditioning experiences. J Anxiety Disord. 2002;6(3):321-329. https://doi. org/10.1016/S0887-6185(02)00103-2

29. Milsom KM, Tickle M, Humphris GM, Blinkhorn AS. The relationship between anxiety and dental treatment experience in 5-year-old children. Br Dent J. 2003;10;194(9):503-6. https://doi.org/10.1038/sj.bdj.4810070

30. Vassend O. Anxiety, pain and discomfort associated with dental treatment. Behav Res Ther. 1993;31:659-66. https:// doi.org/10.1016/0005-7967(93)90119-F

Received on: 18/12/2017

Final version resubmitted on: 3/4/2018

Approved on: 19/5/2018 